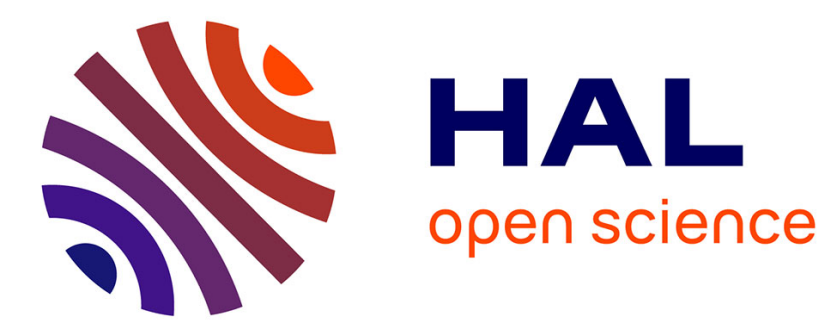

\title{
Preparation and structure of amorphous semiconductor hydrogenated tin
}

\author{
M. Vergnat, G. Marchal, Ph. Mangin
}

\section{To cite this version:}

M. Vergnat, G. Marchal, Ph. Mangin. Preparation and structure of amorphous semiconductor hydrogenated tin. Applied Physics Letters, 1990, 57 (22), pp.2300-2301. 10.1063/1.103893 . hal-02113399

\section{HAL Id: hal-02113399 \\ https://hal.science/hal-02113399}

Submitted on 28 Apr 2019

HAL is a multi-disciplinary open access archive for the deposit and dissemination of scientific research documents, whether they are published or not. The documents may come from teaching and research institutions in France or abroad, or from public or private research centers.
L'archive ouverte pluridisciplinaire HAL, est destinée au dépôt et à la diffusion de documents scientifiques de niveau recherche, publiés ou non, émanant des établissements d'enseignement et de recherche français ou étrangers, des laboratoires publics ou privés. 


\title{
Preparation and structure of amorphous semiconductor hydrogenated tin
}

\author{
M. Vergnat, G. Marchal, and Ph. Mangin \\ Laboratoire de Physique du Solide (U.A.au C.N.R.S. ni 155), Universite de Nancy I, B.P. 239, \\ 54506 Vandowwre les Nancy Cedex, France
}

(Received 13 July 1990; accepted for pubication 17 September 1990)

\begin{abstract}
Evaporation on substrates maintained at $77 \mathrm{~K}$ under an atomic hydrogen flow allows us to prepare amorphous semiconductor tin. The resistivity is very high, $3 \times 10^{3} \Omega \mathrm{cm}$ and the diffraction pattern is typical of the random continuous networks of amomphous germanium and silicon. This structure is stable up to $180 \mathrm{~K}$.
\end{abstract}

Crystalline tin exhibits two allotropic phases with a transition temperature at $13.2^{\circ} \mathrm{C}$. The low-temperature $\alpha$ phase (grey tin) is a zero-gap semiconductor with the fourfold coordinated diamond structure. The interatomic distance is $2.81 \AA$. The high-temperature $\beta$ phase (white din) is metallic with a tetragonal structure, in which each atom is surrounded by four atoms at 3.02 and two atoms at $3.17 \AA$. This raises the question of the feasibility of preparing and of the stability of amorphous semiconductor $a-5 n$ since previous attempts to obtain such a structure were not successful. Vapor deposition of tin on low-temperature substrates always leads to amorphous or microcrystalline metalic tin. ${ }^{1}$

In this letter we show that semiconductor amorphous tin with fourfold coordination can be obtained if tin is deposited at low temperature under a flow of atomic hydrogen. To the best of our knowledge, it is the first time such a phase has been synthesized.

Tin was evaporated from a thermal cell on substrates kept at liquid-nitrogen remperature. The substrates were grids covered with carbon for electron difraction and glass plates for electrical measurements. The tin deposition rate $(2 \AA / s)$ was controlled and monitored with a quartz crystal microbalance system. Hydrogen was introduced through a $1 \mathrm{~mm}$ tungsten tube pointing at the substrate. Atomic hydrogen was produced by themal dissociation in a tungsten tube heated to $2500 \mathrm{~K}$. The hydrogen flow was regulated by maintaining the fotal pressure in the evaporation chamber at $10^{-5}$ Torr.

Transmission electron diffraction was performed in situ at low temperature and during the warming of the samples. The electron diffraction pattems were recorded using a scaming high-energy electron diffraction system (SHEED) operating at $45 \mathrm{kV}$. Electrical measurements were carried out simultareously.

Three types of samples were fabricated:

(a) nonhydrogenated samples: Sn;

(b) samples hyörogenated with molecular hydrogen: $\mathrm{Sn}: \mathrm{H}_{2}$;

(c) samples hydrogenated with atomic hydrogen: $\mathrm{Sn}: \mathrm{H}$

As-quenched Sn and Sn:H exhibit very similar resistivity behavior with a large relaxation process between 100 and $200 \mathrm{~K}$ (Fig. 1). After annealing at room temperature, the resistivity $\rho_{300 \mathrm{~K}}$ is $14.4 \mu \Omega \mathrm{cm}$ with a positive temperature coefficient $\alpha=3 \times 10^{-3} \mathrm{~K}^{-1}$. These values are close to that of crystaline $\beta$-tin $\left(\rho_{273 \mathrm{~K}}=11 \quad \beta \Omega \mathrm{cm}\right.$ and $\left.\alpha=4.7 \times 10^{-3} K^{-1}\right) .^{3}$ The as-quenched Sn:H films exhibit a completely different behavior with a lowtemperature resistivity of $3 \times 10^{3} \Omega \mathrm{cm}$ and a very sudden transition at $180 \mathrm{~K}$ (Fig. 2). At this temperature, the resistivity decreases by eight orders of magnitude in a few seconds. After this transition, the behavior of the resistivity is very similar to that observed in $\mathrm{Sn}_{n}$ and $\mathrm{Sn}_{\mathrm{H}} \mathrm{H}_{2}$ samples. The temperature dependence of the resistivity was studied between 77 and $180 \mathrm{~K}$. Even for samples annealed just below the transition temperature, no thermally activated conductivity following an Arrhenius law has been observed but, as it is the case for pure amorphous silicon and germanium, the temperature dependence of the resistivity was better described by the variable range hopping formula (Mott's law) ${ }^{4}$ :

$$
\sigma=\sigma_{0} \exp \left[-\left(T_{0} / T\right)^{1 / 4}\right]
$$

with a value of $T_{0}$ equal to $10^{7}$.

Figure 3 shows the electron diffraction patterns collected at $77 \mathrm{~K}$ from (b) as-quenched $\mathrm{Sn}$ or $\mathrm{Sn} \cdot \mathrm{H}_{2}$ samples, from (a) as-quenched Sn:H samples, and (c) from samples ( $\mathrm{Sn}, \mathrm{Sn}: \mathrm{H}_{2}$, or $\mathrm{Sn}: \mathrm{H}$ ) annealed at foom temperature. The (c) diffraction pattern is clearly that of $\beta$-tin. The peaks are easily indexed. They are better resolved with some textural changes if an annealing is performed at higher temperature. At first glance, the (b) difraction pattern could be considered as that of an amorphous material. The large

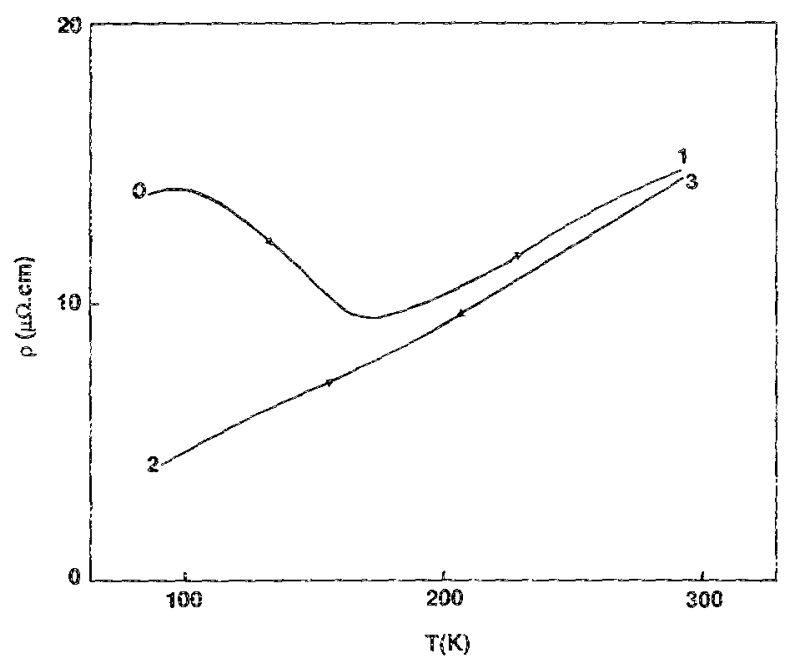

FIG. 1. Variation of the de resistivity (linear scale) vs temperature for tin prepared without hydrogen of with molccular hydrogen. 


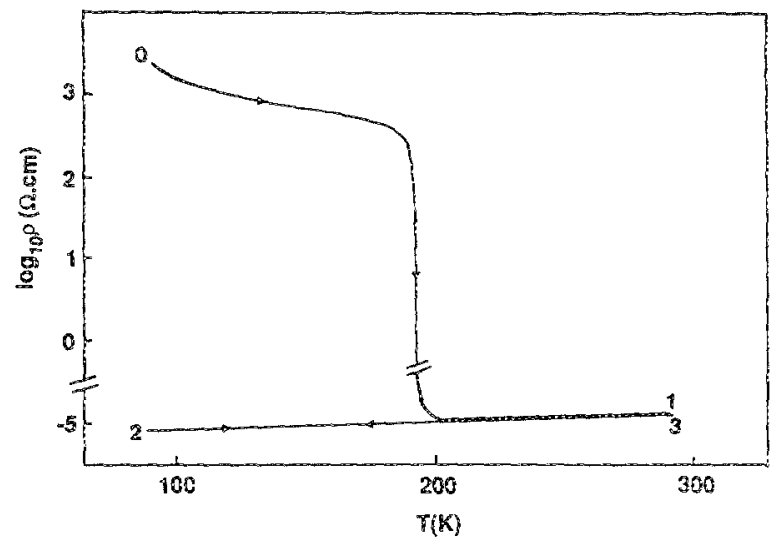

FIC. 2. Variation of the de resistivity (logarithmic scalc) vs temperature for tin evaporated under an atomic hydrogen fiow.

width of the peaks is a point in favor of an amorphous structure. However, the peak positions correspond neither to those of metallic glasses nor to those of amorphous semiconductors; if it is an amorphous structure, it is completely new with presumably a short-range order similar to that found in crystalline $\beta$-tin. On the other hand, the correspondence between the position of the rrst peak of (b) and the (200) and (101) peaks of $\beta$-tin and the lack of a sharp electrical ransition characteristic of a crystallization process (Fig. 1) is in favor of a microcrystalline structure. The shift of the second peak of (b) compared to the (220)and (211) of (c) makes the conclusion uncertain.

Uniake (b), the (a) difiraction pattem is unambiguously that of a etrahedrally bonded semiconductor with two intense peaks and a shoulder on the high scattering vector side of the third peak. The positions of the first two maxima $K_{1}(\mathrm{Sn} \cdot \mathrm{H})=1.69 \AA^{-1}$ and $K_{2}(\mathrm{Sn}: \mathrm{H})=3.00$ $\AA^{-1}$ are in the ratio 1.78 , which is precisely that found in amorphous silicon ${ }^{5}$ where the positions of the peaks are at $K_{1}(a-S i)=2.00 \AA^{-1}$ and $K_{2}(a-\$ i)=3.60 \AA$ ". By considering the Si-Si interatomic distance $d_{\mathrm{Si}-\mathrm{Si}}=2.35 \AA$ given by the radial distribution function of amorphous silicon and by using simple relations of proportionality, $d_{\mathrm{Si}-\mathrm{Si}} K_{1,2}(\mathrm{Si})=d_{\mathrm{Sn}-\mathrm{Sn}} K_{1,2}(\mathrm{Sn})$, we can estimate the interatomic distance in amorphous $\mathrm{Sn}: \mathrm{H}$ as $2.80 \mathrm{~A}$, which is very close to the interatomic distance found in crystalline

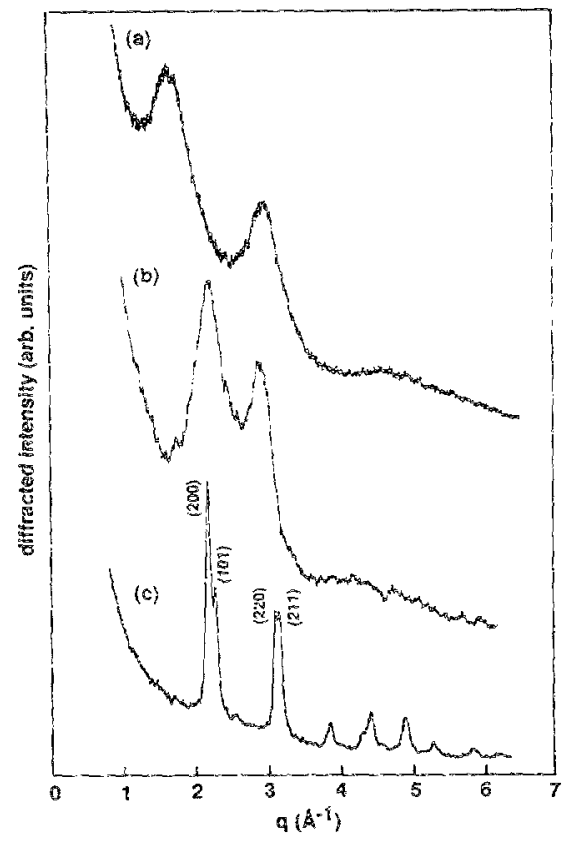

FIG. 3. Electron diffraction patterns of (a) hydrogenated tin at $77 \mathrm{~K}$, (b) whydrogenated in at $77 \mathrm{~K}$, and (c) crystallized tin.

$\alpha$-Sn. Moreover, the resistivity transition observed at 180 $K$ is very sharp (it happens in a few degrees), which is characteristic of crystallization of an amorphous structure.

In conclusion, tin deposited at $77 \mathrm{~K}$ with a fiow of atomic hydrogen is an anorphous semiconductor, similar to amorphous silicon and amorphous germanium, stable ap to $180 \mathrm{~K}$. It remains to be explained why bydrogen stabilizes the tetrahedral symmetry of tin and to try to raise the stability of amorphous semiconductor tin. Multilayers of the type Si:H/Sn:H/Si:H/Sn:H could be a way.

${ }^{1}$ W. Buickel, Z. Phys. 138, 136 (1954).

${ }^{2}$ M. Vergnat, G. Marchal, and M. Piccuch, Rev. Phys. Appl. 22, 1803 (1987).

"Handbook of Chemistry and Physics, 68th ed. 1987-1988 (CRC, Boca Raton, Florida), p. F122.

${ }^{4}$ N. F. Mott and E. A. Davis, Electronic Processes in Non-Crystalline Materials (Oxford Zniversity, Oxford, 1979).

${ }^{5}$ S. C. Moss and J. F. Graczyk, Phys. Rev. Lett. 23, 1167 (1969). 